\author{
Proceedings of the Annual Scientific Meeting of the International \\ Medical Society of Paraplegia Held in Mulhouse, France, in July 1979
}

\title{
THE VALUE OF THE THROMBOELASTOGRAM AS MEANS OF MONITORING THE SUB-CUTANEOUS PREVENTIVE ACTION OF CALCIUM HEPARINATE
}

\author{
By P. Dollfus, M.D., J. J. Bouchier, M.D., P. Henon, M.D., G. Jung, M.D. \\ and M. ISSLER
}

\begin{abstract}
The index of the thrombodynamic potential (I.T.P.) as one of the biological means of controlling the prophylactic effect of sub-cutaneous injections of Calcium Heparinate has been studied in 34 spinal cord injuries during the acute phase. Individual tolerance variations, some of them important, have been noted as well as the necessity of adjusting the doses, according to the time after injury. A biological hypercoagulability has been noted within the first and third month after injury. The interest and the cost of such a method are discussed and further comparative biological investigations, using other methods, have started.
\end{abstract}

Key words: Calcium Heparinate; Prophylaxis; Deep vein thrombosis; Pulmonary embolism; Spinal cord injury.

\section{Introduction}

DEEP vein thrombosis (DVT) and pulmonary embolism (PE) have been a major concern in high risk patients, such as those with spinal cord injuries (SCI) at least, for the great majority of them, during the acute phase, Guttmann (I973). The risk for most of the authors lasts, at least, three to four months after injury. Many have advocated the use of medical treatment besides physiotherapy, passive and active movements, sometimes aided by mechanical devices or placing the patients at 15 degrees in a head-down position. Prophylactic Heparin has been used on a very large scale, as surgery, general or orthopedic, is concerned, before and after the operation, using either i.v. Heparin or sub-cutaneous calcium Heparinate (Calciparin $®$ ), referred in our work as s.c.H. For SCI patients, such a prophylactic method has been used, now, widely and reported in the literature, but authors still discuss the dosis and rhythm of injections during the 24 hours. Most of them agree, now, that a I2- or 8-hourly dosis gives an efficient overall prophylactic coverage after the work of Kakkar et al. (1971-72). This approach has been reported, starting as early as 1972 by Hachen (1974), I973 by Dollfus (I977), I974 by Rocha Casas et al. (1977), I975 by Watson (1978). The continuous prophylactic use of Calcium Heparin has been used by ourselves and by Rocha Casas et al. (1978). Some authors are still using Vitamin $\mathrm{K}$ inhibitors, either as a relay for Heparin (Watson, 1978), or in some instances from the start onwards for a similar period (Silver, 1974). Others have been using platelet aggregation inhibitors from the start, or as a relay (Hachen, I978), and recently Charnley (1978) has given his experience concerning Hydroxochloroquine (Plaquenil ®) to prevent platelet adhesiveness and aggregation in hip surgery. 
Different laboratory investigation methods on DVT have been discussed in the literature, such as the 125 I Fibrinogen uptake tests, ultra-sound flow detection, venous occlusion plethysmography, phlebography (Todd et al., 1976), and have shown that the SCI patient is at a high risk. Hachen (1974) has given in his article all the aspects concerning biological action of different anticoagulants and their biological control. As s.c.H. is concerned, most of the authors take for granted that a uniform random dosis is sufficient without biological laboratory control (Rocha Casas et al., I977; Watson, I978). Partial thromboplastin time (PTT) has been used by Hachen (1974). Cerrato et al. (1978) use PTT, plasma fibrinogen and platelet count as biological guides before neurosurgical operations, adapting their prophylactic dosis according to the plasma Heparin concentration. Other different tests are used in some well-equipped laboratories, such as the measure of the anti-X activity. Nowadays, the kaolin cephalin activated test is more widely used, sometimes, in complement to the Howell test. Dilution protamine sulfate test has also been used (Perkash, I978).

\section{Material}

Thirty-four SCI patients (I977 and I978), Table I, have been put on s.c.H. immediately after injury, for most of them. ${ }^{1}$ This therapy has been continued right through the acute phase and the efficiency of the prophylactic dosis studied, using the thromboelastogram method, mainly on the index of the thrombodynamic potential (ITP), the dosis being adjusted on these results. The results have been compiled and studied with the help of the computer terminal put at our disposal by the Choay Laboratories (656 TEGs have been performed). $2 \cdot 332$ day treatment dosis have been studied.

\section{The thromboelastogram method}

Fresh blood is obtained by straight venous puncture and collected, after discarding the first two millilitres, in a silicone tube containing 9 per cent Calcium

\section{TABLE I}

Population study. Average age $=3 \mathrm{I} \cdot 2$ years ( 15 to 74 )

\begin{tabular}{lccc}
\hline & $\begin{array}{c}\text { Complete } \\
\text { lesions }\end{array}$ & $\begin{array}{c}\text { Incomplete } \\
\text { lesions }\end{array}$ & Total \\
\hline Level distribution & & & \\
$\quad$ Cervical & I & 7 & 8 \\
$\quad$ Thoracic & 9 & 3 & I2 \\
$\quad$ Thoraco-Lumbar & 4 & 7 & II \\
$\quad$ Lumbar & I & 2 & 3 \\
Associated lesions & & & \\
$\quad$ With & 8 & 8 & I6 \\
$\quad$ Without & 7 & II & I8 \\
Sex & & & \\
$\quad$ Male & 8 & I2 & 20 \\
$\quad$ Female & 7 & 7 & I4 \\
Total & I5 & I9 & 34 \\
\hline
\end{tabular}

1 Only three patients did not receive prophylactic s.c.H. before admission. 
Citrate solution. $0.25 \mathrm{ml}$ of this venous blood is, then, introduced in the siliconed tank of a thromboelastograph Hellige. Recalcification is obtained by addition of a $0 \cdot \mathrm{I} \mathrm{ml}$ of a I.29 per cent solution of $\mathrm{CaCl}_{2}$ previously diluted by half. The surface of the blood is immediately recovered by a film of mineral oil. Blood clotting reduces the alternative rotation of a piston, the movements of which are transmitted by a light beam to a photographic registering paper. This gives a 'tuning fork' curve rendering the kinetic and dynamic clotting aspect of the sample examined (Fig. I). $r$ = latency phase between start and the time when blood starts clotting; $k=$ time when the first fibrin formation starts, plotted against the time when the two widening curves reach the distance of $20 \mathrm{~mm} ; r+k=$ the kinetic aspect of clotting, $r$ being perhaps more reliable. Emx represents the maximum elasticity and ITP is the Emx ratio. Normal, for this study, is an ITP of 5 to 20 ; below $3^{\mathrm{k}}$, one must consider that the blood coagulation is markedly hypocoagulable and over 20 there is a potential risk of hypercoagulation which needs to be corrected. Technical or human errors are always possible and results sometimes have been rechecked.

Total blood

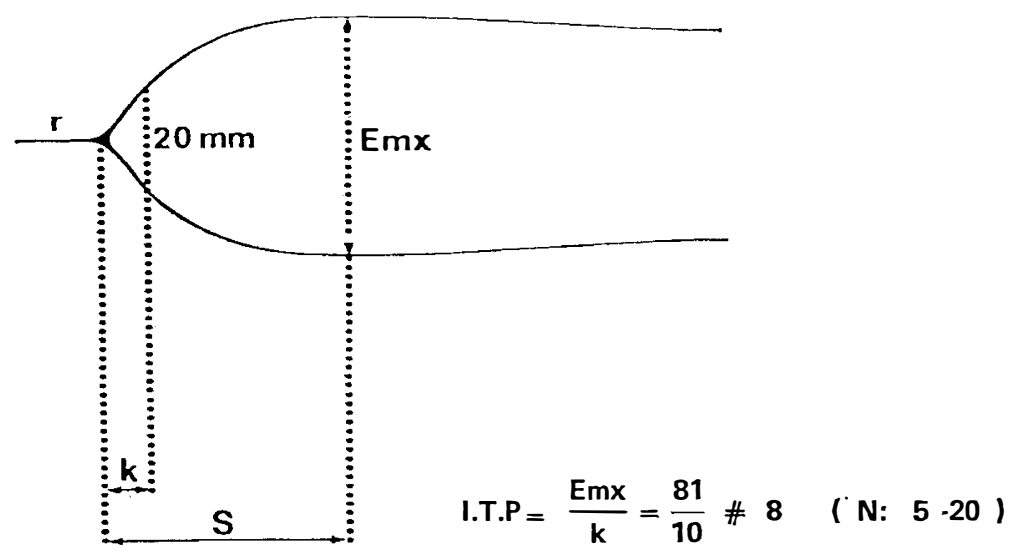

FIG. I

Index of thrombodynamic potential.

In the beginning of our study, residual Heparinemia, Anti-thrombin III levels, fibrinogen, platelet counts, Howell clotting time, have been studied in correlation with the TEG. This was performed only on four patients and showed the great sensitivity of TEG compared to the other parameters. Their interpretation was not practical as to allow us to adapt our dosis with a minimal useful accuracy. For financial and technical reasons, it was decided to continue on the TEG basis. Lately, we have started to correlate our TEG with the Cephalin Kaolin time.

\section{Results}

Table II gives the average injection dosis and duration of the treatment in days, also giving distribution of the total number of days of treatment for the 34 patients.

Table III gives the distribution of the efficiency of one dosis of s.c.H. based on the TEG result, according to: $(a)$ the level of the lesion; $(b)$ complete or incomplete; and $(c)$ with or without associated lesions; this leading to readjustment 


\section{TABLE II}

Average injection dosis and duration of the treatment in days. Total number of days of treatment for 34 patients

\begin{tabular}{|c|c|c|c|c|}
\hline & Number & $\begin{array}{l}\text { Average injection } \\
\text { dosis (ml s.c.H.) } \\
\text { (thrice a day) }{ }^{\star}\end{array}$ & $\begin{array}{l}\text { Average duration } \\
\text { of treatment } \\
\text { (days) }\end{array}$ & $\begin{array}{l}\text { Total no. of } \\
\text { days of } \\
\text { treatment }\end{array}$ \\
\hline \multicolumn{5}{|l|}{ Level distribution } \\
\hline Cervical & 8 & 0.30 & 85 & 68I \\
\hline Thoracic & 12 & 0.29 & 63 & 757 \\
\hline Thoraco-Lumbar & II & 0.33 & 6I & 669 \\
\hline Lumbar & 3 & 0.34 & 75 & 225 \\
\hline Complete & 15 & 0.31 & 72 & I074 \\
\hline Incomplete & 19 & 0.31 & 66 & 1258 \\
\hline \multicolumn{5}{|l|}{ Associated lesions } \\
\hline With & I6 & 0.32 & 74 & II 85 \\
\hline Without & I 8 & $0 \cdot 30$ & 64 & I 147 \\
\hline Total & 34 & $0.3 \mathrm{I}$ (=7.500 i.u.H.) & 69 & \\
\hline
\end{tabular}

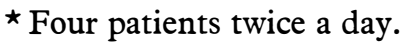

TABLE III

Distribution of the efficiency of one dosis of s.c.H. on TEG result, according to: (a) the level of the lesion; $(b)$ complete or incomplete; and (c) with or without associated lesions; leading to readjustment of the treatment. One can see that the highest risk of potential hypercoagulation is in the cervical group and the associated lesions group

\begin{tabular}{|c|c|c|c|c|c|c|}
\hline & & \multicolumn{2}{|c|}{$\begin{array}{l}\text { Hypercoagulation } \\
\text { risk } I T P>20\end{array}$} & \multicolumn{2}{|c|}{$\begin{aligned} & \text { ISOC. }=\text { ITP: } 5-20 \\
& \text { HYPOC. }=\text { ITP: }<3(.)\end{aligned}$} & \multirow[t]{2}{*}{$\begin{array}{l}\text { Total } \\
\text { TEG }\end{array}$} \\
\hline & & No. TEG & $\%$ & No. TEG & $\%$ & \\
\hline \multicolumn{7}{|c|}{ (a) Level distribution } \\
\hline & Cervical & 68 & $35 \cdot 5$ & I24（I2） & $64 \cdot 5(6 \cdot 25)$ & 192 \\
\hline & Thoracic & 54 & $24 \cdot 3$ & I69（I4） & $75 \cdot 7(6 \cdot 2)$ & 223 \\
\hline & Thoraco-Lumbar & 48 & $26 \cdot 5$ & I33 (I9) & $73 \cdot 5(10 \cdot 4)$ & I8I \\
\hline & Lumbar & 12 & $20 \cdot I$ & $48(5)$ & $79 \cdot 9(8 \cdot 3)$ & 60 \\
\hline$(b)$ & Complete & 87 & $27 \cdot 8$ & 225 (I8) & $72 \cdot 2(5 \cdot 7)$ & 312 \\
\hline & Incomplete & 95 & $27 \cdot 6$ & $249(32)$ & $72 \cdot 4(9 \cdot 3)$ & 344 \\
\hline \multicolumn{7}{|c|}{ (c) Associated lesions } \\
\hline & With & 107 & $3 I \cdot 9$ & $228(3 \mathrm{I})$ & $68 \cdot I(9 \cdot 2)$ & 335 \\
\hline & Without & 75 & $23 \cdot 3$ & 246 (I9) & $76 \cdot 7(5 \cdot 9)$ & 321 \\
\hline
\end{tabular}

of the treatment. The highest risk of potential hypercoagulation is in the cervical group as in the associated lesion group.

Table IV shows the average efficiency on TEG results, considering a total number of $656 \mathrm{TEGs}$ based on a given standard dosis : $\mathrm{ml}$ or $\frac{1}{2} \mathrm{ml}$ of s.c.H. (I $\mathrm{ml}$ Calciparin $₫=2 \cdot 500$ i.u. Heparin).

Table IVb gives an overall mean estimation of efficiency of s.c.H. prophylactic 


\section{TABLE IV}

(a) Average efficiency on TEG results (No. TEG: 656) of a given standard dosis (ml of s.c.H.); (b) overall mean estimation of efficiency of s.c.H. prophylactic treatment based on TEG results, showing that the treatment was considered by this method of being 'adapted' in 64.7 per cent with a hypercoagulation potential risk in 27.7 per cent of the cases and a potential haemorrhagic risk in 7.6 per cent

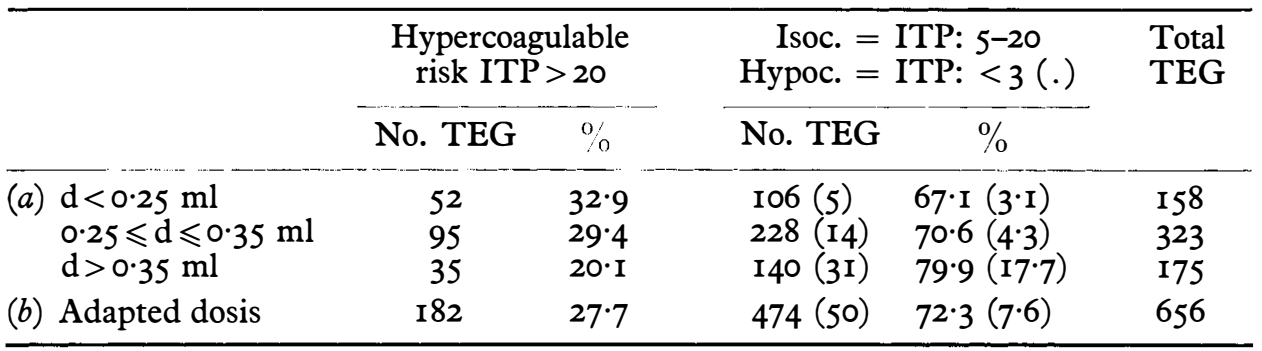

treatment, showing that the treatment was considered by this method of being adapted in 64.7 per cent with a hypercoagulation potential risk in 27.7 per cent of the cases, and a potential haemorrhagic risk in 7.6 per cent cases.

Table $V$ gives the average effect of so-called 'low' (Kakkar et al., 1972), prophylactic dosis of s.c.H. $(<0.25 \mathrm{ml})$ on TEG results, related to spinal cord injury level. One can estimate that for a 'low' dosis, the cervical group shows a potentially higher risk.

TableVI shows an average effect of 'high' prophylactic s.c.H. dosis $(>0.35 \mathrm{ml})$, related to the spinal cord injury level. Hypercoagulation diminishes but with a moderate relative raise of a potential haemorrhagic risk for all groups.

Table VII shows the average effect on TEG results of a 'low' prophylactic dosis $(0.25 \mathrm{ml})$, related to: (a) complete or incomplete lesions, and (b) with or without associated lesions. One can notice that the highest significant risk is with the associated lesions group which, therefore, needs more adaptation of the dosis.

Table VIII gives the average effect on TEG results of 'high' prophylactic dosis of s.c.H., related to: $(a)$ complete or incomplete lesions; and (b) with or without

\section{TABLE V}

Average effect of 'low' prophylactic dosis of s.c.H. $(<0.25 \mathrm{ml})$ on TEG results, related to spinal cord injury level. One can estimate that for a 'low' dosis the cervical group shows potentially a higher risk

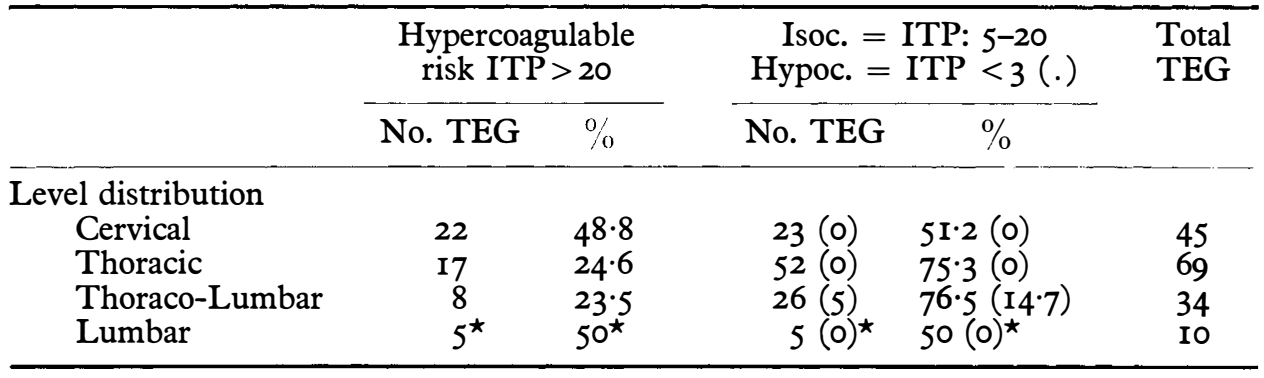

* Not very significant (only 5 cases). 


\section{TABLE VI}

Average effect of 'high' prophylactic s.c.H. dosis $(0.35 \mathrm{ml})$ related to the spinal cord injury level (TEG results). Here the hypercoagulation risk diminishes but with a moderate elevation of the haemorrhage risk for all groups

\begin{tabular}{|c|c|c|c|c|c|}
\hline & \multicolumn{2}{|c|}{$\begin{array}{l}\text { Hypercoagulation } \\
\text { risk ITP }>20\end{array}$} & \multicolumn{2}{|c|}{$\begin{array}{r}\text { Isoc. }=\text { ITP: } 5-20 \\
\text { Hypoc. }=\text { ITP: }<3(.)\end{array}$} & \multirow[t]{2}{*}{$\begin{array}{l}\text { Total } \\
\text { TEG }\end{array}$} \\
\hline & No. TEG & $\%$ & No. TEG & $\%$ & \\
\hline \multicolumn{6}{|l|}{ Level distribution } \\
\hline Cervical & 9 & $2 \mathrm{I} \cdot 4$ & $33(7)$ & $78 \cdot 6(\mathrm{I} 6)$ & 42 \\
\hline Thoracic & 8 & 15 & $45(8)$ & 85 (I5) & 53 \\
\hline Thoraco-Lumbar & I6 & $25 \cdot 8$ & 46 (II) & $74 \cdot 2(17 \cdot 7)$ & 62 \\
\hline Lumbar & $I^{\star}$ & 12 & I6 (5) & $88(27)$ & I7 \\
\hline
\end{tabular}

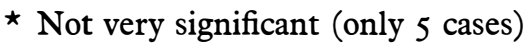

\section{TABLE VII}

Average effect on TEG result of 'low' prophylactic dosis $(<0.25 \mathrm{ml})$ related to: (a) complete or incomplete lesion; and (b) with or without associated lesions. One can notice that highest significant risk is with the associated lesions group and therefore needs more adaptation of the dosis

\begin{tabular}{lcccccc}
\hline & $\begin{array}{c}\text { Hypercoagulation } \\
\text { risk ITP }>20\end{array}$ & & \multicolumn{2}{c}{$\begin{array}{c}\text { Isoc. }=\text { ITP: } 5-20 \\
\text { Hypoc. }=\text { ITP: }<3(.)\end{array}$} & \multirow{2}{*}{ Total } \\
\cline { 2 - 3 } & No. TEG & $\%$ & & No. TEG & $\%$ & \\
\hline Complete & 24 & $3 \mathrm{I} \cdot \mathrm{I}$ & & $53(0)$ & $68 \cdot 9(0)$ & 77 \\
Incomplete & 28 & $34 \cdot 5$ & & $53(5)$ & $65 \cdot 5(6 \cdot \mathrm{I})$ & $8 \mathrm{I}$ \\
With associated lesions & 27 & $43 \cdot 5$ & & $35(5)$ & $56 \cdot 5(8)$ & 62 \\
Without associated lesions & 25 & 26 & & $7 \mathrm{I}(0)$ & $74(0)$ & 96 \\
\hline
\end{tabular}

\section{TABLE VIII}

Average effect on TEG results of 'high' prophylactic $(0.35 \mathrm{ml})$ dosis of s.c.H., related to: $(a)$ complete or incomplete lesions; and $(b)$ with or without associated lesions. In both methods, one can see that the complete lesions showed a higher hypercoagulation risk

\begin{tabular}{|c|c|c|c|c|c|}
\hline & \multicolumn{2}{|c|}{$\begin{array}{l}\text { Hypercoagulation } \\
\text { risk ITP }>20\end{array}$} & \multicolumn{2}{|c|}{$\begin{aligned} \text { Isoc. } & =\text { ITP: } 5-20 \\
\text { Hypoc. } & =\text { ITP: }<3(.)\end{aligned}$} & \multirow[t]{2}{*}{$\begin{array}{l}\text { Total } \\
\text { TEG }\end{array}$} \\
\hline & No. TEG & $\%$ & No. TEG & $\%$ & \\
\hline Complete & 22 & $25 \cdot 5$ & 64 (I4) & $74 \cdot 5(16 \cdot 2)$ & 86 \\
\hline Incomplete & I3 & $14 \cdot 6$ & $76(17)$ & $85 \cdot 4(19 \cdot I)$ & 89 \\
\hline With associated lesions & 22 & 23 & 74 (I9) & 77 (I9·7) & 96 \\
\hline Without associated lesions & I3 & $\mathrm{I} 6 \cdot 4$ & $66(12)$ & $83 \cdot 6(15 \cdot 1)$ & 79 \\
\hline
\end{tabular}


associated lesions. Both ways, one can see that the complete lesions tend to have a higher risk of hypercoagulation and those with associated lesions.

Figure 2 gives the average overall variation plotted curve of a s.c.H. efficient dosis, related to time (for the 34 patients studied), using ITP and $r+k$.

Figure 3 gives the average plotted curves of s.c.H. the efficient dosis, related to time and presence or absence of severe associated lesions (head, thorax, bone fractures).

To illustrate this study, we would like to give a clinical Case Report:

A 5I-year-old man, North African, sustained after a 9 metre fall, while at work, an immediate cauda-equina lesion, incomplete below $\mathrm{L}_{3}$, complete below $\mathrm{S} 2$, motor complete below $\mathrm{L}_{3}$ due to a fracture dislocation of $\mathrm{LI}_{\mathrm{I}}$ vertebra. He was seen immediately after the accident by the paraplegist on duty at the Hospital of Mulhouse and, thereafter, transported to the Spinal Cord Unit four hours after. The vertebral reduction was satisfactory, using postural reduction. He received Solumedrol @ 80 mgrs, three times a day, which was decreased gradually within one week. Anticoagulation by s.c.H. was started, using from the start $0.3 \mathrm{ml}$ three times a day. The next day, a hematuria was macroscopically present. The IVP was normal and s.c.H. was diminished (the ITP was normal the first day, the next day it showed a value of $\mathrm{I} \cdot 2)$. Therefore, s.c.H. was reduced to $0.1 \mathrm{ml}(2.500$ i.u.) three times a day, then twice daily. For such an anticoagulation, the ITP remained at the same values between 2 and 5. This being considered as abnormally low. From the start, active physiotherapy was performed twice a day and he was placed in the usual $15^{\circ}$ head-down position. The fourth week, suddenly, after a digital evacuation of faeces, he became distressed and dyspnoeic with a very rapid shallow breathing.

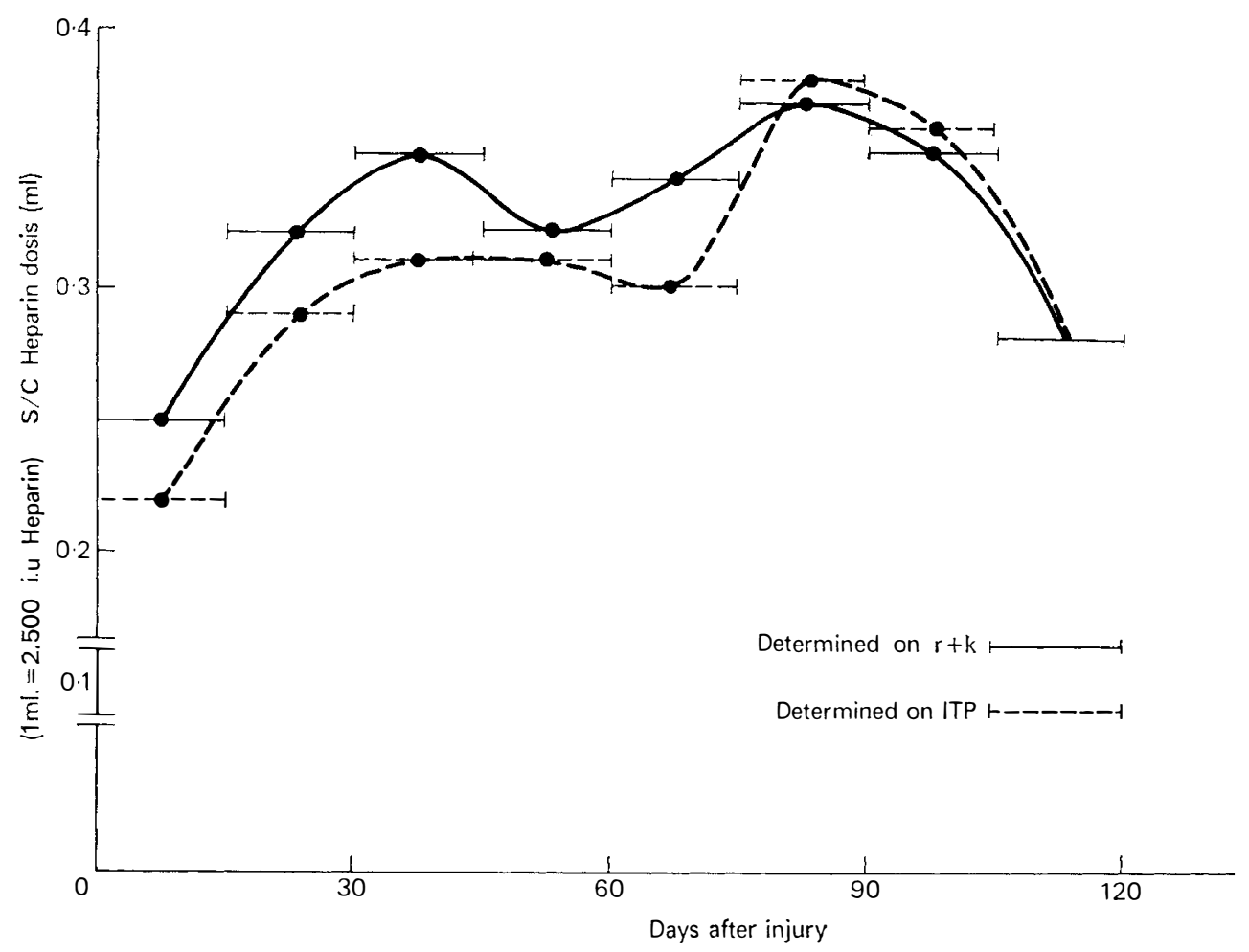

FIG. 2 


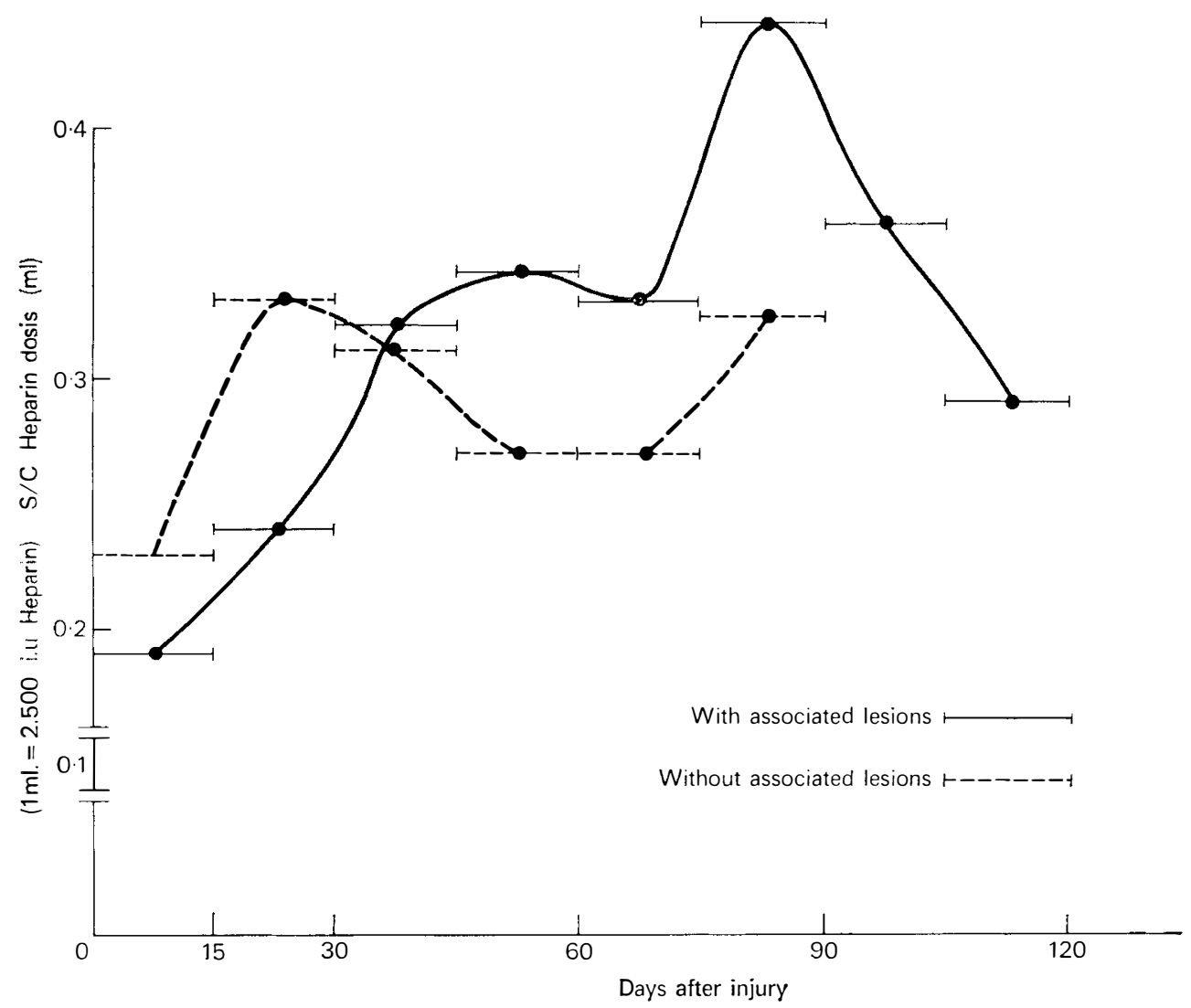

FIG. 3

PE was confirmed by ECG and marked P.a.02 lowering. His respiratory difficulties increasing, isotopic lung perfusion scanning was performed, confirming the diagnosis and a clip was put on the vena cava. Anticoagulation by s.c.H. was resumed at $0.5 \mathrm{ml}$ three times a day. Fifteen days after, he presented a cardio-vascular collapsus and was transferred to the Surgical Resuscitation Unit of Mulhouse, the diagnosis of an extending thrombosis below the clip being confirmed by phlebography. Anticoagulation was, then, raised to $0.7 \mathrm{ml}$ three times a day. The Howell clotting time was eight minutes and the ITP 0.7 (!). Fifteen days later, he was operated in neurosurgery for an intracerebral large bleeding hematoma, clinically revealed by a left side hemiparesis of which he happily recovered completely. Anticoagulation, naturally, was stopped. A full blood clotting mechanism examination was performed and showed a diminution of prothrombin (45 per cent) as well as the Proconvertin and Steward factor (43 per cent), probably a congenital deficiency of one of the factors. In spite of all, through all these events, his neurological motor status improved below the level of the lesion, the sensory level remaining unchanged. He walks now with two crutches and, as he was going out of the Centre, one of the sliding doors hit him, he fell and broke his hip (!), which was operated ...

This case report illustrates the difficulties which can occur sometimes, using prophylactic s.c.H. It also shows reliability of the thromboelastogram method. Why this patient had such a hypocoagulable values, having, first, a PE and, then, 
an extending thrombosis below the clip, is very difficult to explain. Further investigations are, now, performed to confirm or not the congenital defect.

\section{Discussion}

Many laboratory biological tests have been proposed and, at the same time, criticised as the clotting mechanism is extremely complex, many parameters having to be investigated. What we wanted to show, is the individual susceptibility to Heparin shown by many SCI patients we have to treat. This individual susceptibility seems to be enhanced, according to the level of the lesion, also if there is, or not, important associated lesions. Body surface and weight should also be taken into account. The different curves show that there is, in fact, two peaks of hypercoagulability, one at the end of the first month, the second at the end of the third month. We have no real explanation for this, maybe the first peak is in relation with the many biological changes which occur immediately and after the spinal cord injury enhanced by recumbency. We did not find any clinical correlation with these curves, having only one case with a massive non-fatal pulmonary embolus. Another case, studied in the series had a massive pulmonary embolism ${ }^{1}$ (before his admission here) 8 days after his SCI treated elsewhere. His life was saved by a vena cava clip, which delayed his admission. One year before his SCI, he already had a pulmonary embolism following an accident with severe left hip and knee fractures. On the other hand, he had three haemorrhagic complications, which must be included into the study and in the three instances (in two patients) twice hypocoagulation could be related. ITP values were below 3. We have not used any other method of detecting thrombosis in this series, only once using phlebography which was negative in a suspected prolonged hypercoagulation biological state. The interest of s.c.H. used prophylactically is great but the cost is relatively high as well as the laboratory tests. We think that the results warrant the costs. Nevertheless, further comparative biological investigations, using other methods have started.

\section{RÉSUMÉ}

L'index de potentiel thrombodynamique (I.P.T.) en tant que moyen biologique de contrôle du traitement anti-coagulant prophylactique par l'Héparine sous-cutannée, a été étudié chez 34 blessés médullaires à la phase aiguë. Nous avons remarqué des variations individuelles importantes ainsi que la nécessité d'adapter les doses en fonction du temps. Il existe en particulier, une poussée d'hypercoagulabilité biologique durant le premier mois ainsi qu'au courant du troisième mois après le traumatisme. L'intérêt et le coût de cette méthode est aussi envisagé. Nous avons d'ailleurs commencé de nouvelles études utilisant d'autres paramètres biologiques.

\section{ZUSAMMENFASSUNG}

Der Index des Thrombodynamischen Potential als Überwachung der prophylactischen Wirkung des sub-kutanen Heparin wurde studiert in 34 Querschnittgelähmten gleich in der akute Phase. Es wurde bemerkt, individualisierte Variationen, manchmal wichtig, und auch die Notwendigkeit einer Anpassung der Dosis gegenüber der Zeit nach dem Unfall. Man beobachtet eine Hyperkoagulierung am ersten und dritten Monat nach dem Unfall. Die Kosten und der Vorteil auf solche Behandlung wurde diskutiert, und Verschiedene biologische Untersuchungen mit anderen Methoden haben begonnen.

${ }^{1}$ He was treated by Heparin only after his embolism. 


\section{REFERENCES}

Cerrato, D., Ariano, C. \& Fiacchino, F. (1978). Deep vein thrombosis and low-dose heparin prophylaxis in neurosurgical patients. f. Neurosurgery, 49, 378.

Charnley, J. (1978). Low Friction Arthroplasty of the Hip. Theory and practice. Springer Verlag.

Dollfus, P. (I973). Closed injuries of the dorsal and dorsilumbar spine and cord. Proceedings of the Nineteenth Veterans Administration Spinal Cord Injury Conference, 29-3I October 1973.

GutTMANN, L. (1973). Spinal Cord Injuries, comprehensive management and research. Blackwell Scientific Publications.

Hachen, H. J., Rossier, A. B., Bouvier, C. A. \& Ritschard, J. (1974). Deficiency within the extrinsic prothrombin activator system in patients with acute spinal cord injury. Paraplegia, 12, 132.

HACHEN, H. J. (1974). Anticoagulant therapy in patients with spinal cord injury. Paraplegia, 12, 176.

HACHEN, H. J. (I979). Personal communication.

KAKkaR, V. V., Field, E. S., Nicolaides, A. N., Flute, P. T., Wessler, S. \& Yin, E. T. (I97I). Low doses of heparin in prevention of deep vein thrombosis. Lancet, 25 Sept., 669.

Kakkar, V. V., Corrigan, T., Spindler, J., Fossard, D. P., Flute, P. T., Crellin, R. Q., WESSLER, S. \& YIN, E. T. (I972). Efficacy of low doses of heparin in prevention of deep vein thrombosis after major surgery, a double blind randomised trial. Lancet, i 5 July, IOI.

Perkash, A., Prakash, V. \& Perkash, I. (I978). Experience with the management of thromboembolism in patients with spinal cord injury: Part I. Incidence, diagnosis and role of some risk factors. Paraplegia, 16, 322.

RABY, C. (1967). Paramètres responsables des variations individuelles de la sensibilité vis-à-vis de l'héparine. Archives Méditerranéennes de Médecine, 3, I33.

RABY, C. (1975). Contrôle de l'héparinothérapie. International Heparin Symposium, Londres, I8-I9 juillet 1975 .

RabY, C. (1975). Le concept thrombo-embolique. Principes du diagnostic biologique et du traitement. Symposium sur l'Héparine, Fano (Italie), 20 septembre 1975.

Rocha, Casas E., Perez, Sanchez M., Recio, Arias C. \& Plaja, Masip J. (I977-78). Prophylaxis of venous thrombosis and pulmonary embolism in patients with acute traumatic spinal cord lesions. Paraplegia, 15, 209.

SILVER, J. R. (I974). The prophylactic use of anticoagulant therapy in the prevention of pulmonary embolism in one hundred consecutive spinal injury patients. Paraplegia, I2, 188 .

Todd, J. W., Frisbie, J. H., Rossier, A. B., Adams, D. F., Als, A. V., Armenia, R. J., SASAHARA, A. A. \& Tow, D. E. (1976). Deep venous thrombosis in acute spinal cord injury: a comparison of 125 Fibrinogen leg scanning, impedance plethysmography and venography. Paraplegia, I4, 50.

Watson, N. (1978-79). Anti-coagulant therapy in the prevention of venous thrombosis and pulmonary embolism in the spinal cord injury. Paraplegia, 16, 265. 